\title{
OS USOS DO CORPO: DOS SACRIFÍCIOS “PRIMITIVOS” ÀS RELIGIÕES “ATUAIS”- RESENHA
}

Ana Carolina Capellini Rigoni

\section{Resumo}

No livro Sobre o Sacrificio, Mauss e Hubert falam sobre a função social do sacrifício religioso, que para eles concentra-se na prática de certos rituais realizados com o objetivo de iniciar ou manter o contato com deus, ou ainda deuses, dos quais o indivíduo tem necessidade. Percebemos uma profunda relação entre estes rituais com o corpo do fiel, pois são os gestos realizados durante o ritual que dão significado a ele. Isto torna a obra relevante a todos que se propõem a estudar o corpo em seus aspectos culturais e sociais, pois são diversas as religiões que compõem a sociedade contemporânea.

\section{Palavras-Chaves}

Sacrifício; Rituais religiosos; Corpo.

\section{THE USE OF THE BODY: THE SACRIFICES 'PRIMITIVE”' RELIGIONS TODAY - REVIEWS}

Ana Carolina Capellini Rigoni

\begin{abstract}
In the book Sacrifice: its nature and function, Mauss and Hubert tell about the social function of the religious sacrifice, which, according to them, is concentrated on the practice of certain rituals that are performed aiming to initiate or to keep the contact with the god, or gods, whom the subject needs. We noticed a deep relation between such rituals and the believer's body, for it is the gestures performed during the ritual that give meaning to it. This makes the work relevant to all those who are willing to study the body in its cultural and social aspects, as the religions comprising the contemporaneous society are various.
\end{abstract}

\section{Key-Words}

Sacrifice; Religious rituals; Body. 


\section{INTRODUÇÃO}

Esta obra de Marcel Mauss (1872-1927), que teve como colaborador Henri Hubert (1872-1950), foi publicada originalmente em 1899 com o nome de Essai sur la nature et la fonction du sacrifice. Publicada recentemente no Brasil, o livro recebeu o título de Sobre o Sacrifício. Mesmo cem anos depois de sua produção original, a obra dos autores é relevante pela possibilidade que seus pensamentos nos conferem ao estudarmos as religiões atuais e os usos do corpo que nela se inscrevem. Esta obra é significativa no sentido em que avança em relação aos estudos realizados na época sobre os rituais religiosos. Os autores desencadeiam idéias que superam as do próprio tio de Mauss, Émile Durkheim. Os escritos de Mauss e Hubert foram pertinentes não só para a época como também para entendermos as diversas crenças e seus ritos nos dias de hoje. A obra nos ajuda a compreender quais foram as mudanças e os resquícios deixados pela religião primitiva, que ainda podemos encontrar na sociedade atual. Afinal, os estudos de hoje sobre a religião devem dizer mais do que os clássicos já disseram, mas de certa forma, precisam partir deles para seguirem outros rumos.

No livro, Mauss e Hubert falam sobre a função social do sacrifício religioso, que para eles concentra-se na prática de certos rituais realizados com o objetivo de manter o contato com a esfera divina. Percebemos que existia uma profunda relação entre estes rituais e o corpo do fiel que o praticava, pois eram justamente os gestos realizados durante o ritual que davam significado a ele. Na sociedade contemporânea estes rituais primitivos já não ocorrem, ou pelo menos não com a mesma forma e freqüência com que ocorriam nas sociedades primitivas. Muita coisa mudou ao longo do tempo, mas há algo que permanece: o uso e a importância do corpo nas práticas religiosas. O modo como o corpo estava presente nos rituais citados pelos autores não é o mesmo nos dias atuais, mas o fato é que ele ainda se constitui como o principal "objeto" utilizado pelo homem religioso na busca do sagrado. Isto torna a obra relevante tanto aos estudiosos das ciências da religião quanto àqueles que se propõem a estudar o corpo na sociedade contemporânea, em seus aspectos sócio-culturais, nos quais a religião se constitui como componente significativo.

Na busca de definir a função social do sacrifício, os autores iniciam o texto apresentando uma idéia de Tylor ${ }^{1}$ que diz que, o sacrifício é originalmente uma dádiva que o selvagem faz aos deuses, aos quais é conveniente a ele se ligar. Tylor diz que, estes mesmos deuses começam a se afastar dos homens, e para

\footnotetext{
${ }^{1}$ TYLOR, Edward B. La Civilization Primitive. Paris, 1876-78.
} 
que isto não aconteça criam-se os ritos sacrificiais, que têm como objetivo fazer chegar aos seres espirituais as coisas sagradas, mantendo assim um contato entre eles. No entanto, os autores vão dizer que

se a teoria de Tylor descreve bem as fases do desenvolvimento moral do fenômeno, ela não explica o seu mecanismo, o qual Mauss e Hubert julgavam necessário fazê-lo. Foi este o empreendimento dos autores, o qual demonstraremos a seguir.

É importante deixar claro que o termo "sacrifício" é utilizado pelos autores para designar certos rituais praticados por indivíduos de um determinado grupo para iniciar ou manter o contato com deus, ou ainda deuses, dos quais têm necessidade. Ou seja, o sacrifício é composto de atos e rituais que servem para colocar em contato o mundo do sagrado com o mundo do profano. Neste sentido, ao pensarmos sobre a teoria de Mauss e Hubert sobre as religiões primitivas, percebemos o significado atribuído ao corpo do indivíduo que pratica o ritual. Percebemos também que, apesar do uso do corpo nas religiões atuais se dar de outra forma, ele ainda é o principal meio utilizado pelo fiel para manter o contato com o divino.

Para os autores, o sacrifício religioso pode ser entendido como tudo que engloba certos rituais, e que não são necessariamente atos que causam dor ou sofrimento, como é de costume pensar em nossa sociedade quando se emprega o termo sacrifício. É claro que, a maioria dos sacrifícios estudados por Mauss e Hubert se dava a partir de rituais nos quais havia uma "vítima" que seria entregue aos deuses. O ritual geralmente acabava com a morte da vítima que era levada pelo deus ao qual tinha sido oferecida. Esta vítima podia ser tanto um animal, um alimento, como um membro da tribo. No último caso, o sacrifício era literalmente corporal, pois o indivíduo entregava seu próprio corpo à morte. $\mathrm{O}$ que não significa que as outras formas de sacrifício, aquelas realizadas com animais ou alimentos não envolvessem o corpo do "sacrificante", através de gestos e expressões realizadas durante o ritual.

Da mesma forma que os autores falam sobre os sacrifícios que envolviam a morte da vítima, eles parecem sustentar a idéia de que o simples ato rotineiro de freqüentar um culto ou uma missa poderia ser entendido como sacrifício. Para os autores, um rito sacrificial não precisa estar necessariamente ligado à religião, mas geralmente está, e com certeza teve origem nela.

Mauss e Hubert afirmam que o sacrifício sempre conferiu ao fiel direitos sobre o seu deus. Pois a partir do momento em que um indivíduo se sacrifica, ele espera um retorno de deus por isso. Este é um conceito que pode ser percebido ainda nos dias de hoje quando observamos as diversas modalidades de religiões 
existentes, e percebemos que, senão em todas, na maioria delas encontramos rituais que servem ou para pedir algo à divindade, ou para agradecer a dádiva já recebida. Para os autores, esta que é uma característica primitiva do sacrifício, não deixa de ser uma espécie de contrato selado com Deus.

Apesar de encontrarem diversos exemplos primitivos de sacrifício, Mauss e Hubert não acreditam, como fez Smith $^{2}$, autor por eles estudado, que todos os tipos de sacrifício tenham derivado de uma forma primitiva e simples. Pois, para os autores, encontramos nas religiões atuais formas variadas de ritos sacrificiais que em nada se parecem com os ritos antigos. O que não significa que não tenham objetivos parecidos, pois como demonstram os próprios autores, "todo sacrifício ocorre sob certas circunstâncias e em vistas de fins determinados" (MAUSS, HUBERT, 2005, p. 101) É justamente da diversidade destes fins buscados pelos fiéis que nascem as várias modalidades de sacrifícios, inclusive os recentes. Os autores afirmam que não há nenhuma religião em que estas modalidades não coexistam em maior ou menor número. Isto demonstra a importância do pensamento dos autores nos dias atuais, em que vemos diversas formas de sacrifícios sendo investidas por diferentes grupos. Os exemplos vão desde os "homens bomba" até os peregrinos que saem em direção ao local sagrado em busca de um fim que justifique sua ação.

Para explicar melhor, os autores tentam definir alguns fatos que designam por "sacrifício". Num primeiro momento, Mauss e Hubert remetem a palavra sacrifício à idéia de consagração, ou seja, em todo sacrifício um objeto passa do domínio comum ao domínio sagrado. O objeto é religiosamente transformado (consagrado). O homem precisa deste objeto consagrado, pois não está em contato imediato com a divindade. Então, este objeto se transforma em intermediário entre o mundo sagrado e o mundo profano.

Outro tipo de sacrifício citado pelos autores é aquele que tem a forma de redenção, ou remissão. Ou seja, o sacrifício como a forma que o homem criou para se redimir com seu deus. É como se fosse uma espécie de prestação de contas, na qual, normalmente é o corpo que deve se sacrificar para pagar a dívida. Se pensarmos neste conceito aplicado aos dias de hoje de forma um tanto quanto "grosseira" poderíamos citar os exemplos das inúmeras pessoas que fazem promessas aos santos para que estes realizem algum pedido. Um exemplo típico é o pagamento através do sacrifício de subir uma escadaria de joelhos.

${ }^{2}$ SMITH, William R. “Sacrifice”. In: Encyclopaedia Britannica. 1875-89. 
Após alguns conceitos sobre os mecanismos que compõe o sacrifício, Mauss e Hubert elaboram um levantamento sobre as classificações do sacrifício. Os autores dividem os rituais em: sacrifícios ocasionais e sacrifícios constantes. O que demonstra que tanto nas crenças antigas, como nas atuais, as cerimônias tinham o tempo certo de acontecer. Logicamente que em cada religião elas ocorrem de formas diferentes e em tempos diferentes.

Os sacrifícios ocasionais são aqueles que não possuem dias certos para acontecer, mas acontecem em ocasiões necessárias como, por exemplo, os ritos sacramentais, os ritos votivos e os ritos expiatórios. Tentando pensar nas religiões nos dias de hoje e fazendo uma comparação com os exemplos dos autores, encontramos algumas cerimônias ocasionais atuais. Alguns exemplos são as cerimônias de batismo, as de casamento, as de primeira comunhão etc.

As cerimônias ou sacrifícios constantes são aqueles que acontecem sempre em dias certos, préestabelecidos, seguindo uma rotina religiosa, ou seja, são os cultos semanais. Mauss e Hubert também falam da freqüência com que devem ocorrer os ritos constantes. Eles precisam ser efetuados entre espaços de tempo que não evoquem a presença de deus com tanta freqüência e nem ao contrário, ou seja, não se pode demorar tanto para participar de um rito a ponto de que haja o abandono de deus.

Para Mauss e Hubert (2005, p. 26) “o sacrifício é um ato religioso que só pode se efetuar num meio religioso e por intermédio de agentes essencialmente religiosos". Ou seja, como exemplo atual de meio religioso podemos citar os templos, as igrejas, enfim, as diversas instituições religiosas existentes. Os agentes religiosos podem ser os padres, os pastores ou dirigentes destas instituições.

Os fiéis, por sua vez, não possuem o caráter religioso e sagrado antes da cerimônia acontecer. Eles são profanos, portanto é preciso que passem pelos ritos que os introduzirão ao mundo sagrado. Para que isto aconteça é preciso purificar o "corpo" do indivíduo, pois é ele que é profano e põe a alma em risco. Ou seja, “o sacrifício é sempre praticado por profanos” ( MAUSS, HUBERT, 2005, 105). Não há sentido em um indivíduo participar de um ritual se ele já estiver puro.

Neste sentido, o ritual de sacrifício é praticado tanto pelos indivíduos que necessitam dele como por indivíduos preparados para realizá-lo. Ou seja, o que os autores nos falam é que em uma cerimônia sacrificial cada um tem o seu papel. Explicando esta divisão de papéis, Mauss e Hubert falam sobre o sacrificador, o sacrificante e a vítima. 
Quanto ao papel do "sacrificador", podemos atribuí-lo nos dias de hoje ao padre ou ao pastor (são os agentes religiosos citados anteriormente). No entanto, os autores falam do papel do "sacrificante" e da

"vítima" de forma que não podemos tecer comparações com os papéis nos ritos atuais. Para eles chamase de sacrificante aquele que recebe os benefícios do sacrifício. Mas, para que isto aconteça é necessário que haja uma vítima. Esta, como já disse anteriormente, pode ser tanto um animal, como um alimento ou o próprio homem. Assim, a vítima servirá de intermediária entre o sacrificante e a divindade. Entendemos que hoje os sacrifícios se dão por outros meios.

Assim como a sociedade, a religião também se modificou ao longo da história. Isto acontece porque a igreja precisa assumir um posicionamento que acompanhe as transformações políticas, culturais e econômicas ocorridas na vida de seus fiéis. Assim, em decorrência destas mudanças, nas crenças atuais, muitas vezes o próprio sacrificante assume o papel da vítima, ou seja, sacrifica-se ele mesmo (não com a morte, salvo raras exceções) para alcançar uma dádiva.

O fato de sacrificar-se, ou de sacrificar uma vítima para conseguir algo, explica um caráter muito particular do sacrifício religioso. "Em todo sacrifício há um ato de abnegação, já que o sacrificante se priva e dá. E geralmente essa abnegação lhe é mesmo imposta como um dever, pois o sacrifício nem sempre é facultativo; os deuses o exigem" (MAUSS, HUBERT, 2005, p. 106). No entanto, Mauss e Hubert deixam claro que essa abnegação não suprime um retorno egoísta.

Se o sacrificante dá algo de si, ele não se dá: reserva-se prudentemente. Se ele dá, é em parte para receber. O sacrifício se apresenta assim sob um duplo aspecto. É um ato útil e uma obrigação. $O$ desprendimento mistura-se ao interesse. Eis porque ele foi freqüentemente concebido sob a forma de um contrato (MAUSS, HUBERT, 2005, p. 106).

Para os autores talvez não haja sacrifício que não se configure em forma de contrato. Para eles as duas partes envolvidas trocam serviços e ambas têm suas vantagens, pois os deuses também têm necessidade dos profanos. Para que o sagrado subsista, é preciso dar-lhe sua parte, e é com a parte dos profanos que se faz essa reserva.

Este talvez seja um dos conceitos trazidos pelos autores que mais se aproximem das religiões atuais, que estão cada vez mais voltadas às conquistas materiais. Os fiéis se sacrificam em busca de uma "boa" vida. Se antes sacrificava-se um animal para que o deus enviasse a chuva, possibilitando uma boa colheita, hoje 
o que se espera em troca é arranjar um bom emprego, salvar os filhos do vício etc. Ou seja, o contrato com deus não é somente um conceito aplicável aos primitivos, ele serve e bem as religiões atuais.

Os sacrifícios "expiatórios" como a realização de uma promessa já feita, são praticados para desligar a pessoa do vínculo moral e religioso que pesa sobre ela. Assim como os sacrifícios de "atribuição" onde o indivíduo quer comprometer a divindade por um contrato - dou para que dês-, são usados até hoje. Ou seja, é preciso ser "bom" para ficar próximo do mundo sagrado, mas para isso é necessária a ajuda de deus. Este, por sua vez, ajuda seu fiel por que tem interesse em sua permanência no "bem".

Refletindo sobre estas noções de sacrifício estudadas por Mauss e Hubert, é possível perceber que apesar de pouco encontramos nas sociedades atuais ritos que culminam com a morte de uma vítima ${ }^{3}$, alguns dos objetivos do ritual antigo ainda permanecem atuais e são mais evidentes em algumas religiões. Ou seja, os ritos como forma de consagração e de prestação de contas ainda são vistos nas religiões atuais. Destaco, como exemplo, principalmente as igrejas evangélicas ${ }^{4}$ e, dentre elas, em especial as mais tradicionais ${ }^{5}$. Nestas denominações religiosas, por seus costumes serem mais conservadores, fica evidente um tipo de educação corporal que recai sobre seus membros de forma rígida e estereotipada. Estes evangélicos se vestem de forma diferente, agem de forma diferente e não fazem as mesmas coisas que fazem as pessoas que não são de sua igreja. Seus corpos são constantemente utilizados para atestarem materialmente sua fé. Cria-se um modelo de "como ser evangélico" que é demonstrado pelo fiel através de seus quesitos corporais. O corpo do evangélico é sempre um meio utilizado por ele para manter contato com Deus e por isso ele deve ser preservado. Cada fiel deve estar atento para não cair em tentação e sua gestualidade deve ser a mais "apropriada" possível dentro dos padrões ditados pela igreja. Este não deixa de ser um tipo de sacrifício corporal. Diferente, é claro, dos exemplos utilizados pelos autores, que correspondem às tribos primitivas, mas com contornos e objetivos semelhantes. Pois como diriam Mauss e Hubert, o sacrifício é composto por ações e rituais que fazem parte da tradição de um determinado grupo e que simboliza o contato deste grupo com o mundo sagrado.

\footnotetext{
${ }^{3}$ Quando digo que encontramos poucos é porque ainda existem religiões, normalmente as afro-descendentes que utilizam-se de sacrifícios de animais como forma de oferenda aos deuses.

${ }^{4}$ Destaco esta vertente religiosa não por acreditar que ela seja a única que tem relação com estes tipos de rituais e comportamentos, e sim porque foi esta vertente que estudei com mais aprofundamento durante a pesquisa de mestrado.

${ }^{5}$ As grejas que fazem parte do pentecostalismo são divididas em três vertentes: o Pentecostalismo Clássico, estabelecido no país com a Congregação Cristã no Brasil, em 1910 e com a Igreja Evangélica Assembléia de Deus, em 1911; o Deuteropentecostalismo, surgido entre 1950 e 1960 no Brasil e o Neopentecostalismo, que inicia-se nos anos de 1970. É justamente sobre as igrejas da primeira vertente que estou me referindo, pois são normalmente elas que mantêm seus fiéis sob a rígida vigilância e sob a obrigação de cumprir a "ferro e fogo" as normas da igreja. As igrejas da segunda e da terceira vertente, na sua maioria encontram-se modernizadas e preocupam-se menos com as questões dos velhos costumes e conservadorismos, o que não faz de seus membros indivíduos com características tão marcantes do ponto de vista corporal (MARIANO, 1999).
} 
Os objetivos dos rituais primitivos ainda são muito parecidos nos dias de hoje, o que mudou é a forma como eles se dão e principalmente a forma como o corpo é utilizado no meio religioso moderno. Além de o corpo ser um componente significativo nos cultos e missas atuais, aprendendo a se comportar e a gestualizar de maneira específica dentro da igreja, ele também é alvo de vigilância e cuidados fora dela. Os fiéis aprendem modos de se comportar que devem ser seguidos e respeitados não só nos momentos de culto e sim na vida cotidiana. Eles sabem que estão sempre sob a vigília, não somente de Deus, mas de todos os membros de sua igreja. Neste sentido, o indivíduo é alvo de uma educação religiosa que servirá para atestar sua crença religiosa diante da sociedade a partir dos gestos e dos usos que faz do próprio corpo.

A partir daí, podemos perceber que as idéias dos autores são pertinentes aos estudos que pretendem compreender o uso do corpo nas diferentes sociedades. Entender o modo como as sociedades praticam os rituais religiosos é, de certa forma, entender o modo como estas mesmas sociedades fazem uso de seus $\operatorname{corpos}^{6}$. Os sacrifícios religiosos são compostos por diversos gestos corporais que dão significado às crenças religiosas dos indivíduos que dele participam. Se no período estudado por Mauss e Hubert os sacrifícios se davam a partir de rituais específicos, em locais específicos (sagrados), com dia e hora marcados e com a prática de gestos elaborados especificamente para aquele ritual, hoje os membros das igrejas têm outra perspectiva sobre o uso do corpo no plano religioso.

O corpo é utilizado de diversos modos pelas diferentes religiões. Não se entrega o próprio corpo ou um animal a morte para um deus (pelo menos não com a mesma freqüência que o povo estudado pelos autores o faziam), mas paga-se penitência de diversas formas. Para não falar somente das igrejas evangélicas, lembro de algumas religiões nas quais os membros costumam rezar ajoelhados. Em outras e as evangélicas são novamente um exemplo - costuma-se estabelecer vestimentas próprias a seus membros. Algumas ainda estabelecem proibições quanto aos usos do corpo para algumas atividades e assim por diante. Isto demonstra que apesar dos religiosos atuais utilizarem o corpo de maneiras diferentes dos primitivos estudados por Mauss e Hubert, o corpo continua a ser um dos principais alvos da religião.

\footnotetext{
${ }^{6} \mathrm{O}$ modo como cada indivíduo faz uso do próprio corpo é um tema também abordado por Mauss em seu texto intitulado As técnicas corporais, contido no livro Sociologia e Antropologia, 2003.
} 
Se atentarmos hoje para os usos do corpo pelas diversas religiões, perceberemos que é significativo o lugar que ele ocupa neste contexto. Ao contrário de ser somente a alma do indivíduo religioso que deve ir em busca de um "mundo sagrado" é o seu corpo o mais responsabilizado pelo alcance ou não deste mundo. Exemplos como o consumo da hóstia (corpo de Cristo) pelos féis católicos, o "passe espiritual" que visa a transfusão de energias ao corpo daqueles que freqüentam o espiritismo e o batismo sob a forma de conversão para os evangélicos - para não citar outros rituais presentes nas inúmeras religiões -, são exemplos do modo como o corpo está simbólica e factualmente presente no interior da vida religiosa.

Mauss e Hubert finalizam sua obra nos mostrando que se tomássemos o sacrifício como algo pertencente apenas à esfera imaginária - e que tudo isto é um jogo de imagens - ficaríamos cegos para o fato de que todos estes ritos são realidades verídicas. Pois as noções religiosas, por serem objetos de crença, existem objetivamente como fatos sociais. As coisas sagradas são coisas sociais. Ou seja, entendemos que, para os autores, a condição necessária para uma religião ser considerada verdadeira é simplesmente a crença que se tem nela. Assim, compreendemos que a função social do sacrifício está nos símbolos sociais que o crente exprime para si mesmo.

Desta forma, fica-nos a contribuição de Mauss e Hubert, quanto a compreensão dos rituais religiosos, sejam eles "primitivos" ou contemporâneos, no que diz respeito a suas relações com o uso do corpo.

\section{REFERÊNCIA DA OBRA RESENHADA}

MAUSS, M.; HUBERT, H. Sobre o sacrificio. São Paulo: Cosac Naify, 2005. 174p.

\section{REFERÊNCIA COMPLEMENTAR}

MARIANO, R. Neopentecostais: sociologia do novo pentecostalismo no Brasil. São Paulo: Loyola, 1999. MAUSS, M. Sociologia e antropologia. São Paulo: Cosac Naify, 2003. 


\section{Ana Carolina Capellini Rigoni \\ Faculdade de Educação Física - UNICAMP}

\section{Referência do artigo:}

\section{ABNT}

RIGONI, A. C. C. Os usos do corpo: dos sacrifícios "primitivos" às religiões "atuais". Conexões, v. 6, n. 1, p. 86-95.

\section{APA}

Rigoni, A. C. C. (2008). Os usos do corpo: dos sacrifícios "primitivos" às religiões "atuais". Conexões, 6(1), 86-95.

\section{VANCOUVER}

Rigoni, ACC. Os usos do corpo: dos sacrifícios "primitivos" às religiões "atuais". Conexões, 2008, 6(1): 86-95. 